LUCIANA OQUENDO PEREIRA LANCHA

\title{
OBESIDADE E RESISTÊNCIA À AÇÃO DA INSULINA: ALTERAÇÕES MOLECULARES, BIOQUÍMICAS E ESTRUTURAIS
}

Tese apresentada ao Programa de PósGraduação em Biologia Celular e Tecidual do Instituto de Ciências Biomédicas da Universidade de São Paulo, para obtenção do Título de Doutor em Ciências.

Área de concentração: Biologia Celular e Tecidual

Orientador: Prof. Dr. Antonio Herbert Lancha Junior

Co-orientadora: Profa. Dra. Marília Seelaender 


\section{RESUMO}

LANCHA, O.P.L. Obesidade e resistência à ação da insulina: alterações moleculares, bioquímicas e estruturais. 2009. 64 f. Tese - Instituto de Ciências Biomédicas da Universidade de São Paulo, São Paulo, 2009.

$\mathrm{O}$ risco aumentado de mortalidade e morbidade associado à obesidade tem sido alvo de muitos estudos que tentam elucidar os aspectos da Síndrome Metabólica, caracterizada por algumas doenças metabólicas como resistência à insulina, hipertensão, dislipidemia. Está bem estabelecido que fatores genéticos têm influência neste aumento dos casos de obesidade; no entanto, o aumento significativo destes casos nos últimos 20 anos, dificilmente poderia ser explicado por mudanças genéticas que tenham ocorrido em tão curto espaço de tempo. Sendo assim, os principais fatores envolvidos no desenvolvimento da obesidade têm sido relacionados com fatores ambientais, como ingestão alimentar inadequada e redução no gasto calórico diário. Apesar de muitos estudos tentarem elucidar as alterações metabólicas decorrentes da obesidade, poucos trabalhos têm analisado as conseqüências da dieta hiperlipídica sobre o metabolismo de aminoácidos. Assim, o objetivo deste estudo foi verificar os possíveis mecanismos responsáveis pelo desenvolvimento da intolerância à glicose após a ingestão de dieta hiperlipídica em ratas saudáveis. Ratas Wistar foram alimentadas, ou com dieta hiperlipídica $(\mathrm{GH})$, ou com ração comercial (GC), por diversas semanas. Os animais alimentados com dieta hiperlipídica por 60 dias apresentaram redução na expressão gênica de Glut 4 (GC 0.7356 \pm 0.0501 vs. GH $0.6086 \pm 0.0571$ ) e do receptor de insulina (GC $0.9689 \pm 0.1458$ vs. GH $0.3046 \pm 0.0842$ ). A dieta hiperlipídica também promoveu redução na atividade da hexoquinase e aumento na atividade de diversas enzimas, como citrato sintase, aspartato aminotransferase e BCAA transaminase, indicando adaptação nas vias metabólicas, com aumento da atividade do ciclo de Krebs e maior utilização de aminoácidos em reações anapleróticas. Contudo, não foi encontrado qualquer modificação na ultraestrutura muscular. A dieta hiperlipídica deste estudo foi eficiente em promover intolerância à glicose em ratas saudáveis e desencadear modificações nas vias metabólicas envolvidas na oxidação de lipídios e aminoácidos.

Palavras-chave: Obesidade. Dieta hiperlipídica. Resistência à insulina. Mecanismos bioquímicos. 


\begin{abstract}
LANCHA, O. P. L. Obesity and insulin resistance: molecular, biochemical and ultra structural adaptations. 2009. 64 p. PhD thesis - Instituto de Ciências Biomédicas, Universidade de São Paulo, São Paulo, 2009.

Obesity has been reported as a worldwide epidemic, independently of economic conditions. The possible causes of increased mortality and morbidity associated with obesity have been focused by many studies that attempt to understand the metabolic syndrome, one of the consequences of obesity. This syndrome is characterized by various metabolic disorders such as insulin resistance, hypertension and dyslipidemia. It is widely known that genetic factors influence the prevalence of obesity. However, the increasing rate of obesity over the last 20 years cannot be explained by changes in the gene pool. In this way, the major factors involved in obesity are related to environmental aspects as dietary intake and reduced energy expenditure. Although many studies to try to elucidate the current metabolic alterations of the obesity, few works have analyzed the consequences of the high fat diet on the amino acid metabolism. Thus, the aim of this study was to verify the possible mechanisms responsible for developing glucose intolerance after a high fat diet intake in healthy female rats. Female Wistar rats were fed either with high fat diet (FD) or with the control diet (CD) for several weeks. The rats fed with a high fat diet for 60 days presented impaired Glut 4 (CD $0.7356 \pm 0.0501$ vs. FD $0.6086 \pm 0.0571$ ) and insulin receptor (CD $0.9689 \pm 0.1458$ vs. FD $0.3046 \pm 0.0842)$ gene expression. High fat diet promoted a reduced activity of hexokinase and increased activity of several enzymes such as, citrate synthase, aspartate aminotransferase and BCAA transaminase, indicating an adaptation in the metabolic pathway, with increase activity of Krebs cycle and increased usage of amino acids in anaplerotic reactions. However, we could not find any changes in the muscle ultra structure. The high fat diet used in this study was efficient in inducing glucose intolerance in healthy female Wistar rats, and provoked changes in the biochemical pathway of the oxidative metabolism.
\end{abstract}

Key Words: Obesity. High fat diet. Insulin resistance. Biochemical pathways. 


\section{INTRODUÇÃO}

Evidências sugerem que a prevalência do sobrepeso e da obesidade tem aumentado em taxas alarmantes, tanto nos países desenvolvidos, como nos países em desenvolvimento. Cerca de dois terços da população adulta americana, por exemplo, demonstra sobrepeso, ou já obesidade (NATIONAL CENTER FOR HEALTH STATISTICS, 2006). O primeiro, segundo e terceiro National Health and Nutrition Examination Surveys (NHANES-I, NHANES-II e NHANES III apud KUCZMARSKI et al., 1994), conduzidos nos Estados Unidos de 1971-1974, 1976-1980 e 1988-1991, respectivamente, mostraram que, apesar dos 33 bilhões de dólares movidos pela indústria de "como perder peso", o número de casos de obesidade vem aumentando significativamente, sem diferenças raciais, ou sociais. Em 1976-1980, a estimativa feita pelo NHANES mostrou que 25,4\% dos adultos entre 20-74 anos apresentavam sobrepeso (IMC > 27,5 kg/m²); entre 1988-1991, a estimativa aumentou para 33,3\% (KUCZMARSKI et al., 1994); no NHANES de 1999-2000, mais de 64\% desta população enquadrava-se no sobrepeso, percentual este que se manteve estável na avaliação realizada entre 2001-2002 (HEDLEY et al., 2004).

A obesidade é considerada uma pandemia (Worl Health Organization (WHO), 1998; POPKIN e DOAK, 1998). No caso do Brasil, as mudanças demográficas, sócioeconômicas e epidemiológicas ao longo do tempo permitiram que ocorresse a denominada transição nos padrões nutricionais, com a diminuição progressiva da desnutrição e o aumento da obesidade (MONTEIRO et al., 1995a, 1995b; FRANCISCHI et al., 2000, 2001). Isso se torna um problema de saúde pública uma vez que as consequências da obesidade para a saúde são muitas e variam do risco aumentado de morte prematura a severas doenças não letais, conhecidas como comorbidade associadas à obesidade. A obesidade é frequentemente associada à hiperlipidemia (O’DEA, 1991; DEFRONZO e FERRANNINI, 1991; MCNAMARA et al., 1992) e ao diabetes mellitus não insulino-dependente (NIDDM) (MCNAMARA et al., 1992), duas condições intimamente relacionadas com doenças cardiovasculares (STUNKARD e WADDEN, 1992; BJÖRNTORP e BRODOFF, 1992; DESPRÉS e LAMARCHE, 1994).

Assim que as consequências da obesidade para a saúde foram demonstradas, muitos estudos têm sido realizados com o objetivo de identificar os principais fatores que contribuem para seu desenvolvimento. A importância genética na etiologia da 
obesidade também tem sido foco de pesquisa em todo o mundo. A identificação e sequenciamento do gene $o b$, que codifica o peptídeo leptina, e a descoberta que o defeito neste gene parece ser a simples causa da obesidade em ratos ob/ob (ZHANG et al., 1994) gerou considerável interesse na genética da obesidade. No entanto, o substancial aumento da prevalência da obesidade observado nos últimos 20 anos não pode ser justificado por alterações genéticas que, teoricamente, teriam ocorrido neste pequeno espaço de tempo (HILL e PETTERS, 1998; JEBB, 1999). Deste modo, alguns autores enfatizam o fato de que a diferença na prevalência da obesidade, em diferentes grupos populacionais, está relacionada, preponderantemente, aos chamados fatores ambientais (WHO, 1990; JEBB, 1999), em especial à dieta (WHO, 1990, 1995, 1998; ROLLS e SHIDE, 1992) e à redução da atividade física (WHO, 1990, 1995, 1998; SCHULZ e SCHOELLER, 1994; HAAPANEN et al., 1997; POPKIN e DOAK, 1998; GRUNDY, 1998). Estes aspectos, interagindo, ou não, com fatores genéticos, poderiam explicar o acúmulo de excesso de gordura corporal em grandes proporções na população mundial (MELBY et al., 1998; HILL et al., 2000).

O balanço energético positivo que ocorre, quando o valor calórico ingerido é superior ao gasto, é importante colaborador do desenvolvimento da obesidade, promovendo aumento nos estoques de energia e peso corporal (PEREIRA et al., 1999a; FRIEL et al., 2007). Resultados analisados por nosso grupo de pesquisa demonstraram a alta incidência de sedentarismo na população obesa. Neste estudo, $80 \%$ das participantes não praticava qualquer atividade física (FREITAS et al., 1998). Além disto, os processos de modernização e transição econômica, observados na maioria dos países, têm promovido alterações na industrialização da produção alimentícia que colabora para o consumo de dietas ricas em proteína e gordura e baixa em carboidratos complexos (MAHAN e ESCOTT-STUMP, 1998). Há indícios que o padrão de alimentação hiperlipídica, hiperproteica e hipoglicídica esteja se repetindo também no Brasil. Estudos realizados por nosso grupo com mulheres obesas brasileiras demonstraram que mais de $30 \%$ do total calórico ingerido por esta população era proveniente de lipídios (PEREIRA et al., 1998, 1999b; KLOPFER et al., 1999; FRANCISCHI et al., 1997, 1999a, 1999b), o que demonstra ingestão semelhante à encontrada nos países desenvolvidos, caracterizando esta dieta como ocidentalizada. 
Deste modo, o sedentarismo e os hábitos nutricionais parecem representar o principal fator de risco no desenvolvimento da obesidade mundial (WHO, 1998; PEREIRA et al., 1999a; FRANCISCHI et al., 2000). O Brasil está seguindo esta mesma linha; em 1997, a prevalência de obesidade no país foi estimada em $11 \%$ da população (MONTEIRO e CONDE, 1999), enquanto, em 1989, era de 9,6\% e, em 1974, era de 5,7\% (MONTEIRO et al., 1995b). Em 1975, havia quase dois casos de desnutrição no Brasil para cada caso de obesidade; já em 1997, havia mais de dois casos de obesidade para cada caso de desnutrição. Acompanhando a tendência mundial de desenvolvimento da obesidade, que vem ocorrendo indiscriminadamente nos vários extratos socioeconômicos da população mundial, a população brasileira de baixa renda estava mais susceptível à obesidade (MONTEIRO et al., 2004). Monteiro e colaboradores (2007) avaliaram a evolução da obesidade, utilizando dados de três pesquisas nacionais: "Estudo Nacional de Despesa Familiar" de 1974, "Pesquisa Nacional sobre Saúde e Nutrição" de 1989 e "Pesquisa de Orçamento Familiares" de julho de 2002 a junho de 2003. No primeiro período de quatorze anos (1975-1989), as taxas de obesidade entre homens e mulheres aumentaram 92\% e $63 \%$, respectivamente, e este aumento foi maior na população de baixa renda. No segundo período de quatorze anos (1989-2003), houve incremento ainda maior da obesidade nos homens e estabilidade da incidência de obesidade nas mulheres de forma geral; porém, com aumento de $26 \%$ entre mulheres de baixa renda. Sendo assim, o autor ressalta a importância de se atentar, não só para o aumento da prevalência da obesidade no Brasil, mas também em como estes casos estão distribuídos entre as classes socioeconômicas.

\subsection{Obesidade e Dieta Hiperlipídica}

A literatura indica que não apenas os totais de energia ingerida e gasta regulam a quantidade dos estoques corporais, como proposto por Flatt $(1987,1995)$ e aceito por muitos autores (SWINBURN e RAVUSSIN, 1993; TREMBLAY et al., 1994; MELBY et al., 1998; PRENTICE 1998; HILL et al., 2000). O balanço de cada macronutriente parece possuir um rigoroso controle para ajustar seu consumo com sua oxidação (e viceversa) e manter um estado de equilíbrio. Stubbs e colaboradores (1995) demonstraram que, para cada megajoule (MJ) de aumento nos estoques proteicos em um dia, existiria uma tendência a um balanço energético negativo no dia seguinte de aproximadamente - 
$0.87 \mathrm{MJ}$; para carboidrato esta relação também foi negativa, produzindo alterações no balanço energético no dia seguinte de - 0.38 MJ. Em se tratando de lipídio, este balanço foi positivo, para cada megajoule de lipídio estocado; o balanço energético no dia seguinte tendia a aumentar cerca de 0.42 MJ. Segundo o autor, estes dados sugerem que o aumento nos estoques de proteínas e carboidratos tem o potencial de exercer feedback negativo no balanço energético deste nutrientes, diferentemente do que ocorre com as gorduras (STUBBS et al., 1995). Nesta mesma linha, Flatt (1987) afirma que o balanço de nitrogênio e de carboidratos é facilitado pela capacidade do organismo, em ajustar as taxas de oxidação de aminoácidos e de glicose, respectivamente, em relação a seus consumos alimentares. No caso das gorduras, esse ajuste é bem menos preciso, e o aumento no seu consumo não estimula, proporcionalmente, sua oxidação. Neste estudo, Flatt e colaboradores (1985) avaliaram em homens saudáveis, por calorimetria indireta, a oxidação de lipídio, carboidrato e proteína por 9 horas após o consumo de café da manhã com três variações na quantidade de gordura, mas com a mesma quantidade de carboidrato (300 kcal) e proteína (130 kcal). Assim, o café da manhã controle tinha 53 kcal de lipídio, enquanto, os outros dois tinham 427 kcal deste macronutriente, sendo um com triglicerídeos de cadeia longa e o outro, de cadeia média. Foi utilizado o intervalo de uma semana entre cada experimento. Os autores mostraram que a quantidade de proteína oxidada foi muito semelhante à quantidade ingerida nas três situações, após 9 horas do consumo. Já o total de carboidrato oxidado após $9 \mathrm{~h}$ do consumo alimentar foi semelhante entre as três refeições, porém com valor superior à quantidade calórica ingerida, ocasionando balanço energético negativo deste nutriente (cerca de $-2 \mathrm{kcal}$ ). No tocante à gordura, nas refeições com alto teor deste nutriente, houve balanço energético positivo de cerca de $58 \mathrm{kcal}$, enquanto na refeição com baixo teor de gordura, este balanço foi negativo, aproximadamente $-287 \mathrm{kcal}$. Assim, a eficiência com que o lipídio da dieta é estocado como gordura corporal é alta, atingindo 96\% (WHO, 1998). Em animais, os estudos apontam a alimentação hiperlipídica como componente importante na etiologia da obesidade, já que dietas hiperlípidicas comprovadamente levaram ao excesso de gordura corporal macacos, cães, suínos, esquilos, hamsters e ratos (WILLET, 1998; KATAN, 1999). Deste modo, estudiosos afirmam que o balanço energético é equivalente ao balanço lipídico (SWINBURN e RAVUSSIN, 1993).

Acredita-se que dietas hiperlipídicas conduzam à hiperfagia, ou causem efeitos metabólicos independentemente desta (WEST e YORK, 1998), como redução na 
atividade lipolítica do tecido adiposo (LLADÓ et al., 2002), redução na secreção de leptina (AINSLIE et al., 2000) e/ou limitação na capacidade de atuação da leptina (FREDERICH et al., 1995). Alguns estudos indicam que prejuízo no metabolismo mitocondrial diretamente predispõe mamíferos ao ganho de peso corporal excessivo, quando alimentados com dietas hipercalóricas semelhantes aos hábitos alimentares encontrados nas populações ocidentais (POMPLUN et al., 2007). O estudo de Townsend e colaboradores (2008) utilizou dieta hiperlipídica e dieta hipolipídica com predominância de gordura saturada, tendo verificado que os animas submetidos à dieta hiperlipídica, apesar de terem consumo energético total menor do que o grupo que consumiu dieta hipolipídica, apresentaram maior ganho de peso, mesmo com maiores concentrações de leptina, apontando para mecanismo de resistência à ação da leptina. $\mathrm{O}$ autor ainda ressalta que o aumento da ingestão calórica total não é fundamental para promover aumento de adiposidade com dieta hiperlipídica em ratos.

Além da ação da leptina, sinais vindos do trato gastrointestinal também têm papel importante na regulação do apetite e da ingestão energética. Evidências sugerem que estes mecanismos supressores do apetite e da ingestão calórica podem estar prejudicados no indivíduo obeso (LITTLE et al., 2007). Ainda não há consenso na literatura, mas diversos autores têm tentado esclarecer como os mecanismos, de fome e saciedade, comportam-se no indivíduo obeso. O peptídeo YY, por exemplo, é secretado pelas células do intestino após o consumo de alimentos e age inibindo a ingestão de alimentos; no entanto, já foi demonstrado que, em indivíduos obesos, as concentrações deste peptídeo são menores do que em indivíduos normais, tornando este mecanismo de saciedade menos eficiente no obeso (BATTERHAM et al., 2003). A grelina, por sua vez, sintetizada e secretada, tanto no estômago, como no intestino, age estimulando o consumo de alimentos e, normalmente, encontra-se em concentrações reduzidas, após as refeições; entretanto, já foi demonstrado que, em indivíduos obesos, as concentrações de grelina mantêm-se elevadas, mesmo após o consumo de alimentos, estimulando a fome (ENGLISH et al., 2002). O motivo pelo qual os lipídios da dieta podem conduzir à hiperfagia também deriva de suas propriedades organolépticas (PRENTICE, 1998), tais como alta palatabilidade, textura característica (TAGLE, 1981; ROLLS e SHIDE, 1992) e grande utilidade e versatilidade como ingrediente culinário (PIKE, 1950). Inclusive em ratos, uma dieta hiperlipídica é preferencialmente consumida quando os animais podem escolher entre três rações, sendo cada uma fonte de um dos macronutrientes (MILLER et al., 1994). 
No entanto, alguns autores acreditam que o tipo de lipídio ingerido na dieta também pode influenciar o acúmulo de adiposidade, visto que alguns trabalhos mostram significativa correlação entre percentual de gordura corporal e percentual de gordura saturada e monoinsaturada ingerida na alimentação (ROMIEU et al., 1988). Ratos submetidos a 7 semanas de dieta hiperlipídica (58\% do valor calórico diário), rica em gordura saturada, desenvolveram maior adiposidade corporal, tanto quando comparados a animais alimentados com dietas ricas em ômega-3, ou ômega-6, quanto, quando comparados ao grupo controle, que foi submetido a uma dieta isocalórica pobre em gordura (WANG et al., 2002). Matsuo e Suzuki (1994) demonstraram alteração na afinidade dos receptores $\beta$ adrenérgicos, no tecido adiposo marrom, no coração e no músculo sóleo, decorrente de dieta hiperlipídica rica em ácidos graxos saturados. Awad e Zepp já haviam demonstrado, em 1979, que ratos alimentados com dieta rica em ácidos graxos saturados apresentavam menor taxa de lipólise, do que animais alimentados com dieta rica em ácidos graxos poliinsaturados, devido à menor atividade da lipase hormônio sensível. Outros autores já demonstraram que a ingestão de ácidos graxos saturados promove acúmulo de adiposidade por diminuição da atividade da atividade simpática, no tecido adiposo marrom, coração e músculo esquelético (MATSUO e SUZUKI 1994; TAKEUCHI et al., 1995). A atividade do complexo carnitina palmitoil transferase (CPT) e, consequentemente, a $\beta$ oxidação também foram reduzidas com a ingestão de ácidos graxos saturados no tecido adiposo marrom (TAKEUCHI et al., 1996). De fato, a fluidez da membrana mitocondrial, determinada pela relação colesterol/fosfolipídios e pelas insaturações nos ácidos graxos que compõem os fosfolipídios da membrana, parece estar diretamente relacionada com a atividade da CPT I no fígado (POWER e NEWSHOLME, 1997).

\subsection{Obesidade e Resistência Periférica à Ação da Insulina}

A obesidade é responsável por desencadear um conjunto de desordens metabólicas com complicações vasculares, denominado de Síndrome Metabólica (IVKOVIC-LAZAR et al., 1992). Os componentes dessa síndrome são caracterizados pela hiperinsulinemia e por diferentes intensidades de resistência à insulina, que explicam a relação entre várias anormalidades e a obesidade (HAUNER, 1995). 
Os dois tipos principais de diabetes são: tipo 1, que é originário da destruição nas células pancreáticas produtoras de insulina $(\beta)$, levando geralmente à deficiência sistêmica desse hormônio, e tipo 2, que corresponde predominantemente à resistência à ação da insulina (AMERICAN DIABETES ASSOCIATION (ADA), 1997). Resistência à insulina significa diminuição na capacidade da insulina em estimular a utilização de glicose (KIM et al., 1996), seja com deficiência de insulina, ou com defeito na secreção e/ou utilização (ADA, 1997). Há, também, uma fase intermediária da homeostase normal da glicose e o diabetes, denominado, tanto de intolerância à glicose, como de tolerância à glicose prejudicada, ou diminuída (ADA, 1997).

Embora a obesidade seja apontada como a causa mais comum da resistência à insulina, nem todos os indivíduos obesos desenvolvem esta alteração. De acordo com diversos autores (NIELSEN et al., 2004; LEBOVITZ e BANERJI, 2005; WEISS et al., 2007), o que irá determinar tal alteração metabólica será o local de acúmulo da adiposidade corporal, sendo a deposição de gordura visceral um dos principais responsáveis (WEISS et al., 2007).

Muitos estudos comprovam que há aumento da oxidação lipídica, quando ocorre aumento do gasto calórico, em pacientes obesos que possuem grande ingestão de lipídios e elevadas taxas de lipólise (diretamente relacionado com o estoque de gordura corporal) (GOLAY et al., 1984). Essa preferência de utilização de ácidos graxos livres (AGL), derivado dos estoques de triglicérides como substrato energético, seria responsável pela diminuição da mobilização de glicose via glicogênio. Isto levaria a feedback negativo do glicogênio muscular e hepático sobre a atividade da glicogênio sintase e, consequentemente, no estoque de glicogênio. O resultado é a resistência periférica à ação da insulina e intolerância à glicose. O quadro de diabetes desenvolvese em obesos, após longo período de intolerância à glicose, quando a glicemia não mais retorna ao estado basal e há resistência à ação da insulina (FELBER e GOLAY, 1995), resultando, na maioria dos casos, à hiperinsulinemia.

Em ratos alimentados com excesso de gordura, já se observou desenvolvimento de obesidade (SEGUÉS et al., 1994; GIANOTTI et al., 1988; SCLAFANI e SPRINGER, 1976b; STORLIEN et al., 1986), como afirmado anteriormente, e redução na ação insulínica sistêmica, muscular e em adipócitos (GRUNDLEGER e THENEN, 1982; MILLER et al., 1985; STORLIEN et al., 1986 e 
1996a; ROCCHINI et al., 1997; HAN et al., 1997). Raubenheimer e colaboradores (2006) utilizaram, por 8 semanas, dieta com $45 \%$ de gordura em ratos e observaram, ao final do período, aumento do peso corporal, aumento das concentrações triacilglicerol em 171\%, além de hiperinsulinemia e intolerância à glicose. Já, Nascimento e colaboradores (2006) demonstraram que animais alimentados com dieta hiperlipídica apresentaram menor fosforilação de uma proteína da cascata de sinalização da insulina, a PKB/Akt, denotando reduzida ação e resistência à insulina induzida pela dieta.

O estudo da ingestão hiperlipídica vem recebendo muita atenção, especialmente, quanto às alterações na ação da insulina. Já foram observadas tais alterações, em ratos, com muito pouco tempo de experimento, como 7 dias (MILLER et al., 1985), 10 dias (GRUNDLEGER e THENEN, 1982), 3 semanas (WILKES et al., 1998), ou 4 semanas (HAN et al., 1997). Diversos trabalhos demonstraram que a resistência à insulina ocorre primeiramente, no fígado, em período de tempo muito curto 3 dias, seguida de prejuízo da ação insulínica em diversos grupos de músculo esquelético (OAKES et al., 1997; KRAEGEN et al., 1991) e no tecido adiposo branco e marrom, em 3 semanas (KRAEGEN et al., 1991). Esses efeitos são dependentes, não apenas da quantidade de gordura ingerida, mas também do tipo, em especial do tamanho e número de insaturações (STEIN et al., 1997). A exposição prolongada de adipócitos a ácidos graxos saturados causou resistência à ação da insulina nestas células (HUNNICUTT et al., 1994).

Muitos estudos tentaram identificar as causas das alterações na captação de glicose, em função da alimentação hiperlipídica; no entanto, ainda há muita controvérsia. Acredita-se que alteração nos receptores de glicose possa ser uma das causas do defeito na ação da insulina, principalmente, pela redução nas atividades do transportador de glicose Glut4. Zierath e colaboradores (1997) verificaram prejuízo na atividade do Glut4 no tecido muscular, após a administração de dietas hiperlipídicas em ratos.

Alguns autores supõem que os aminoácidos poderiam ter importantes implicações nos mecanismos pós-receptor de insulina, dificultando a translocação das vesículas portadoras de Glut4 (PEREIRA e LANCHA JR., 2004). Lancha Jr. (1996, 1997a) encontrou transporte de glicose prejudicado no músculo esquelético de ratos Wistar que foram suplementados com aspartato (45 mg/kg/dia) e asparagina (45 mg/kg/dia) 
durante 5 semanas, quando comparados com grupo controle (sem suplementação). Como não foi encontrada, nos ratos suplementados, nenhuma alteração na atividade da enzima tirosina quinase (responsável pela alteração conformacional do IRS-1, durante os primeiros eventos intracelulares) (ZIERATH, 1995; LANCHA JR., 1996), os aminoácidos podem ter interferido em qualquer um dos numerosos episódios pósreceptor.

O elevado consumo de lipídios e baixo consumo de carboidratos na dieta dos indivíduos obesos poderia ser responsável por elevar a concentração plasmática de ácidos graxos livres (AGL) e, consequentemente, aumentar os estoques de gordura no tecido adiposo (LINCHESTEIN et al., 1998). Dietas hiperlipídicas promovem aumento da atividade da carnitina palmitoil transferase I (CPT I) no fígado e no tecido muscular, aumentando a oxidação lipídica (RYU et al., 2005). Segundo Liu e colaboradores (2007), um dos fatores que favorecem maior atividade da CPT I muscular, decorrente de dieta hiperlipídica rica em ácidos graxos insaturados, é a redução da sensibilidade da CPT I ao malonil-CoA. Sintetizado a partir da carboxilação do acetil-CoA, o malonilCoA é substância crítica na regulação do metabolismo de lipídios por fornecer grupos de acetil ativados para síntese de ácidos graxos, e por inibir a CPT I, consequentemente, a $\beta$ oxidação. A alta ingestão de ácidos graxos insaturados aumentaria a fluidez da membrana mitocondrial, reduzindo a inibição da CPT I pelo malonil-CoA (LIU et al., 2007). O aumento do fluxo de ácidos graxos no interior da mitocôndria, segundo Koves e colaboradores (2008), não é acompanhado de completa $\beta$ oxidação, pela incapacidade do ciclo de Krebs se ajustar ao aumento da demanda oxidativa. Por conseguinte, metabólitos se acumulariam no interior da mitocôndria, desencadeando estresse mitocondrial e resistência à insulina. No entanto, estudo realizado por Bruce e colaboradores (2009) demonstrou que, ao produzir super-expressão da CPT I no tecido muscular, a sensibilidade à ação da insulina, decorrente da dieta hiperlipídica, melhorou. Os autores já haviam encontrado aumento da atividade da CPT I, resistência à insulina, aumento das quantidades de triacilglicerol e aumento do depósito lipídico nas membranas celulares com dieta hiperlipídica. Segundo os autores, a obesidade, decorrente da deita hiperlipídica, resulta em aumento da entrada de lipídios na célula com subsequente aumento da oxidação. Entretanto, o aumento na oxidação é quantitativamente menor, do que o aumento da entrada de lipídeo na célula, resultando em incremento do estoque lipídico celular. O acúmulo destas moléculas bioativas de 
lipídios, como ceramidas, diacilgliceróis, poderiam alterar as características lipídicas da membrana celular, interferindo na ação da insulina. Todavia, ao promover superexpressão da CPT I no tecido muscular, na mesma situação de dieta, a resistência à insulina foi minimizada. Sendo assim, os autores sugeriram então que, a entrada dos ácidos graxos na mitocôndria é fator mais crítico na regulação da oxidação de ácidos graxos, do que o restante da via da $\beta$ oxidação e do ciclo de Krebs.

Desta forma, para que este processo seja desencadeado e o ciclo de Krebs aconteça regularmente, há necessidade do fornecimento de oxaloacetato na mesma proporção que acetil-CoA. Em condições normais, aquele que faz este papel é, inicialmente, o glicogênio com pouca participação da glicose plasmática; depois, quando ocorre redução destes estoques, a glicose plasmática assume esta função de fornecimento de oxaloacetato pela via glicolítica e posterior conversão de piruvato à oxaloacetato (NEWSHOLME e LEECH, 1988). No entanto, quando a concentração de glicose e/ou glicogênio está reduzida, ou em decorrência do jejum, ou do baixo consumo de carboidratos na dieta, ou resultante da resistência à insulina, por exemplo, o fornecimento de oxaloacetato fica deficiente. Tentando corrigir esta deficiência, ocorre estímulo para o processamento de aminoácidos pelo tecido muscular. Alguns aminoácidos, como leucina, isoleucina, valina, aspartato e asparagina, podem ser processados no tecido muscular, a fim de gerar intermediários do ciclo de Krebs (como succinato e oxaloacetato), para manter o funcionamento do mesmo. Estes aminoácidos cedem sua cadeia carbônica para gerar intermediários e liberam amônia no interior do tecido muscular. A tabela 1 mostra os aminoácidos metabolizados no tecido muscular, as enzimas responsáveis pela transferência do grupamento amino e que intermediários fornecem.

Tabela 1: Aminoácidos processados no metabolismo muscular e suas respectivas enzimas para fornecimento de intermediários do ciclo de Krebs.

\begin{tabular}{c|c|c} 
Aminoácido & Enzima aminotransferase & Intermediários \\
\hline Aspartato & Aspartato aminotransferase & Oxaloacetato \\
\hline Asparagina & Asparagina cetotransferase & Oxaloacetato \\
\hline Isoleucina & Leucina aminotransferase & Acetil-CoA e Propionol-CoA \\
\hline Leucina & Leucina aminotransferase & Acetil-CoA \\
\hline Valina & Valina aminotransferase & Succinato \\
\hline
\end{tabular}

Adaptada de Newsholme e Leech (1988). 
Com a manutenção do ciclo de Krebs, acontecerá aumento da concentração de citrato que inibirá a fosfofrutoquinase (PFK) (NEWSHOLME e LEECH, 1988), diminuindo a utilização de glicose e, em decorrência, a captação de glicose. Esta é uma das hipóteses levantadas por alguns autores, para a diminuição da captação de glicose e, consequentemente, resistência à ação da insulina.

Outra hipótese, sugerida por alguns autores, como Marshall e colaboradores (1991), para explicar a resistência periférica à ação da insulina diante deste quadro metabólico, constituiria a glicosilação de substâncias pós-receptor de insulina. Esta glicosilação seria proveniente do aumento das concentrações de glicosamina, produto da via das hexosaminas. Neste caso, a amônia liberada na célula muscular, pelo processamento de aminoácidos, seria deslocada para o $\alpha$-cetoglutarato, intermediário do ciclo de Krebs, gerando glutamato. Este e uma amônia sofreriam ação da glutamina sintase, resultando na síntese de glutamina. Este aminoácido é normalmente utilizado como fonte energética, pelas células intestinais e do sistema imunológico. No entanto, mediante a alta produção de glutamina, como consequência da atividade elevada do ciclo de Krebs, ocorreria estímulo da via das hexosaminas. Nesta via, a glutamina e a frutose-6-fosfato, em reação catalisada pela glutamina:frutose-6-P aminotransferase (GFAT), geram glicosamina-6P, além de outros produtos (TRAXINGER e MARSHALL, 1991).

O aumento do metabolismo de aminoácidos, fornecendo oxaloacetato e outros intermediários para o ciclo de Krebs, implica a elevação da capacidade oxidativa celular e, também, pode provocar uma série de alterações estruturais na célula, como aumento do número e tamanho de mitocôndrias (Figura 1) (LANCHA JR. et al., 1997b). Outros estudos também evidenciaram alterações estruturais com a suplementação de aminoácidos, e os autores justificaram que este resultado poderia ser consequência do aumento do turnover proteico celular (RENNIE et al., 1981), ou do aumento do fluxo de cálcio mitocondrial, devido ao maior número e tamanho das mitocôndrias, podendo estimular proteases cálcio-dependentes, resultando em lesões estruturais (SUZUKI e OHNO, 1990). Entretanto, poucos estudos têm discutido a relação do acúmulo de gordura corporal e o metabolismo de aminoácidos com a finalidade de averiguar quais modificações, a elevada ingestão de lipídios poderia provocar nas vias metabólicas de aminoácidos. 

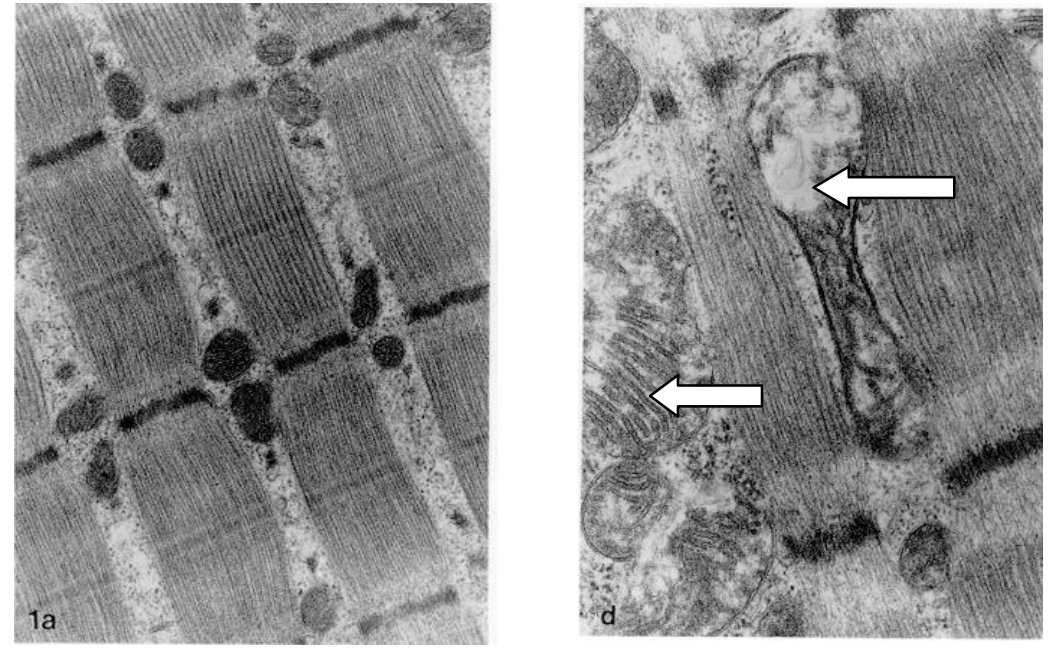

Figura 1: Sóleo de rato sedentário controle (1a) aumento de 15.000x, sóleo de rato suplementado agudamente, com aspartato e asparagina (d) aumento de 40.000x (LANCHA JR., 1993; LANCHA JR. et al., 1997b).

\subsection{Modelos Experimentais de Obesidade}

O estudo da obesidade em humanos, provavelmente, responderia a muitas dúvidas correntes neste tópico. No entanto, pesquisas com humanos têm óbvias limitações éticas, financeiras, além de estudo em animais permitir maior quantidade e profundidade de indagações e resultados. Além disto, animais de laboratório podem ser mantidos em condições rigidamente controladas, consumindo dieta controlada e ser mantidos livre de patógenos e germes. Mesmo que estes modelos animais não possam ser considerados exatamente os modelos de obesidade em humanos, eles ainda são de grande valor no estudo das condições bioquímicas, fisiológicas e patológicas necessárias para o acúmulo excessivo de adiposidade. Nos últimos 20 anos, aumentou muito o conhecimento sobre diversos fatores, que contribuem para o desenvolvimento da obesidade e as consequências endócrinas e metabólicas desta doença. Muito deste conhecimento foi derivado de estudos em modelos de obesidade animal (SCLAFANI e SPRINGER, 1976a).

Diversas formas geneticamente hereditárias de obesidade estão descritas na literatura (PEREIRA et al., 2003b). Alguns roedores (como ratos Sprague-Dawley) são particularmente propensos a desenvolver obesidade pela dieta rica em gordura, ou dieta de cafeteria devido à herança poligênica. Alguns autores acreditam que esta predisposição genética para o desenvolvimento da obesidade com dietas de alta densidade energética é um modelo mais realista e apropriado para o estudo da obesidade humana (FESTING, 1979; YORK, 1992). Entretanto, algumas alterações 
encontradas na obesidade em humanos não ocorrem nestes modelos genéticos de obesidade animal, como aumento da massa magra e algumas diferenças hormonais (JAMES et al., 1979). Desta maneira, fica claro que o estudo da obesidade em animais que possuem alterações genéticas tem diversas limitações e, sendo assim, alguns modelos podem ser utilizados apenas na avaliação de alterações específicas decorrentes da obesidade, considerados inapropriados para outras investigações sobre esta mesma doença e suas consequências metabólicas.

Além disto, devido ao fato de o rápido aumento mundial nos casos de obesidade ter sido relacionado com sedentarismo (DENGEL et al., 1998; SEIDELL, 1999) e maior disponibilidade e consumo de alimentos (KEYS et al., 1981; WHO, 1998; SEIDELL, 1999), muitos estudos têm sido realizados com modelos denominados de "modelos não-genéticos de obesidade". Deste modo, muitas análises têm tentado desenvolver obesidade em animais de laboratório, apenas aumentando a ingestão alimentar (SCLAFANI, 1992). Contudo, em roedores, por exemplo, é muito difícil aumentar a quantidade calórica ingerida voluntariamente, mesmo quando a dieta é flavorizada.

Todavia, o desenvolvimento da obesidade é possível mesmo sem aumento da quantidade de alimento ingerido, porque mudanças na composição de nutrientes, ou na forma da dieta podem alterar a eficiência na utilização do alimento e, consequentemente, aumentar os estoques de gordura por caloria consumida. Na prática, o aumento da densidade da dieta pode resultar em acréscimo do total calórico ingerido, ou em aumento da ingestão de calorias de determinado macronutriente, resultando no crescimento de gordura corporal. Dietas com alto teor de carboidratos e/ou alto teor de lipídios, além da dieta de cafeteria, têm sido utilizadas para desenvolver obesidade em ratos. Muitos estudos foram desenvolvidos, utilizando a chamada dieta de cafeteria, quando vários alimentos, normalmente encontrados em supermercados e cafeterias (como cookies, chocolate, salame, queijo, etc.), são colocados à disposição dos animais. Esta técnica tinha como objetivo aproximar o consumo dos ratos do consumo realizado pelas sociedades modernas, nas quais grande parte das refeições é feita em cafeterias, fast foods, caracterizando uma ingestão com alto teor de gordura, denominada de "dieta ocidental" (WHO, 1990, 1998; ROLLS e SHIDE, 1992; MONTEIRO et al., 1995b; FRANCISCHI et al., 1999a). De fato alguns trabalhos demonstram aumento da quantidade de gordura em animais alimentados com este tipo de ração (SCLAFANI e SPRINGER, 1976a); no entanto, algumas limitações são encontradas neste tipo de 
alimentação. Em estudo piloto realizado em nosso laboratório, foi possível verificar a dificuldade de controlar e avaliar o consumo destes diferentes alimentos pelos animais. No grupo experimental, a ingestão alimentar foi extremamente heterogênea e de difícil avaliação, visto que um dia após os alimentos serem colocados nas gaiolas dos animais (gaiolas individuais), não era possível separar cada alimento e calcular seu consumo, a fim de averiguar qual havia sido a ingestão dos animais em termos de macronutrientes e, também, que tipo de lipídio estava sendo consumido. Esta dificuldade na medição da ingestão e da variabilidade na seleção dos nutrientes, entre os animais submetidos a esta alimentação, tem sido motivo de muita controvérsia, principalmente em estudos sobre a indução da termogênese pela dieta (MOORE, 1987; ROTHWELL e STOCK, 1988; ARGILÉS, 1988.).

O aumento no conteúdo de gordura corporal pode ser alcançado, incrementando a quantidade de gordura na dieta; entretanto, é preciso evitar a redução da relação proteína e energia com intuito de não prejudicar o desenvolvimento e crescimento dos animais estudados. Na prática, dietas contendo $60 \%$ de gordura e $30 \%$ de proteína foram utilizadas inicialmente, com a mistura de ovos e manteiga; todavia, recentemente se tem utilizado banha de porco e caseína a fim de reduzir os custos da preparação da ração. Esta composição também permite alta ingestão de ácidos graxos saturados semelhante à observada em dietas ocidentalizadas. A última Pesquisa de Orçamento Familiar publicada pelo Instituto Brasileiro de Geografia e Estatística (IBGE) encontrou que a participação dos lipídios na disponibilidade domiciliar de alimentos nacional correspondia a $27,6 \%$ e destes, $31,5 \%$ era de ácido graxo saturado (BRASIL, 2004). Resultados encontrados por nosso grupo demonstraram alta ingestão de ácidos graxos saturados na dieta de mulheres obesas: $62,4 \%$ da ingestão de lipídios da dieta era composta por ácido graxo saturado (observações não publicadas), o que corresponde a $17 \%$ do valor calórico total. Segundo a Amercian Heart Association (2009) a ingestão de ácidos graxos saturados não deve exceder 7\% do total de calorias ingeridas diariamente. Na tentativa de desenvolver modelos experimentais, que permitam o estudo da obesidade e suas consequências, esta alta ingestão de ácidos graxos saturados é muito interessante, visto que já foi demonstrada a contribuição deste tipo de gordura no prejuízo da sensibilidade à insulina, decorrente da obesidade (HUNNICUTT et al., 1994). Esta alteração insulinêmica parece ter alta correlação com outras patologias associadas, como hipertensão, dislipidemia (HAFFNER et al., 1992) e aterosclerose (DEFRONZO e FERRANNINI, 1991). 
Com a finalidade de avaliar as consequências deste padrão alimentar, já havia sido desenvolvida uma ração hiperlipídica, a fim de promover a obesidade em ratas Wistar saudáveis, com consequente intolerância à glicose. A ração promoveu acúmulo de gordura corporal já após 40 dias de consumo, e resultou em maior glicemia e insulinemia após 60 dias de ingestão (PEREIRA, 2003a). Por conseguinte, visto que, muitos estudos têm sido direcionados para obesidade e metabolismo de carboidratos e lipídios, e poucos têm discutido a relação do acúmulo de adiposidade corporal e do metabolismo de aminoácidos; o objetivo deste trabalho foi verificar possíveis alterações do metabolismo de aminoácidos, decorrente da ingestão de dieta hiperlipídica, com consequente desenvolvimento da resistência periférica à ação da insulina, verificando provável modificação ultraestrutural na musculatura esquelética. 


\section{CONCLUSÃO}

A dieta hiperlipídica, utilizada neste estudo, provocou alterações enzimáticas indicativas de maior atividade oxidativa, tanto do metabolismo de lipídios, como de aminoácidos, após 60 dias.

A dieta também promoveu prejuízo na tolerância à glicose após 60 dias, indicado pelas alterações encontradas na curva glicêmica e menor atividade da hexoquinase no músculo sóleo e gastrocnêmio. Também houve redução da expressão gênica de Glut4 e IR no grupo que consumiu ração hiperlipídica.

Não foram encontradas alterações nas concentrações de glicogênio entre os grupos, tampouco na ultraestrutura das células musculares.

Este estudo permite então concluir que, a dieta hiperlipídica promove alterações no metabolismo de aminoácidos e que, estas adaptações podem estar relacionadas com o desenvolvimento da resistência periférica à insulina decorrente deste tipo de ingestão alimentar. 


\section{REFERÊNCIAS ${ }^{1}$}

AINSLIE, D.A.; PROIETTO, J.; FAM, B.C.; THORBURN, A.W. Short-term, high-fat diets lower circulating leptin concentrations in rats. Am. J. Clin. Nutr., Bethesda, v. 71, p. 438-442, 2000.

ALP, P.R.; NEWSHOLME, E.A.; ZAMMIT, v. A. Activities of citrate synthase and NAD+-linked isocitrate dehydrogenase in muscle from vertebrates and invertebrates. Biochem. J., London, v. 154, n. 3, p. 389-700, 1976.

AMERICAN DIABETES ASSOCIATION. Report of the Expert Committee on the diagnosis and classification of diabetes mellitus. Diabetes care, New York, v. 20, p. 1183-1197, 1997.

AMERCIAN HEART ASSOCIATION. AHA Recomendation: Fat. Disponível em:

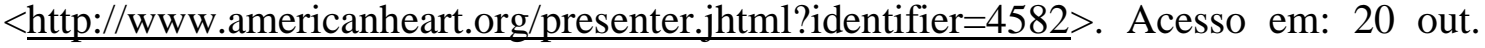
2009.

ANÇÃO, M.S.; CUPPARI, L.; TUDISCO, E.S.; DRAIBE, S.A.; SIGULEM, D. Nutri Versão 2.5: Programa de Apoio à Nutrição (software). CIS/EPM - UNIFESP - Centro de Informática em Saúde - Escola Paulista de Medicina/Universidade Federal de São Paulo. São Paulo, 1999.

ANGERMULLER, S.; FAHIMI, D.H. Imidazole-buffered osmium Tetroxide: an excellent stain for visualization of lipids in transmission Electron microscopy. Histochem. J., London, v. 14, p. 823-825, 1982.

ARGILÉS, J.M. The rise and fall of the cafeteria diet: some observations. J. Nutr., Bethesda, v. 118, p. 1593-1594, 1988.

AWAD, A.B.; ZEPP, A.E. Alteration of rat adipose tissue lipolytic response to norepinephrine by dietary fatty acid manipulation. Biochem. Biophys Res. Commun., New York, v. 86, n. 1, p. 138-144, 1979.

BATTERHAM, R.L.; COHEN, M.A.; ELLIS, S.M.; LE ROUX, C.W.; WITHERS, D.J.; FROST, G.S.; GHATEI, M.A.; BLOOM, S.R. Inhibition of food intake in obese subjects by peptide YY3-36. N. Engl. J. Med., Boston, v. 349, p. 941-948, 2003.

\footnotetext{
${ }^{1}$ De acordo com: ASSOCIAÇÃO BRASILEIRA DE NORMAS TÉCNICAS. NBR 6023: Informação e documentação: referências: elaboração. Rio de Janeiro, 2002.
} 
BJÖRNTORP, P.; BRODOFF, B.N. Obesity. Philadelphia: J.B. Lippincott Company, 1992.

BORST, S. E.; LEE, Y.; CONOVER, C. F.; SHEK, E. W.;BAGBY, G. J. Neutralization of tumor necrosis factor-alpha reverses insulin resistance in skeletal muscle but not adipose tissue. Am. J. Physiol., Baltimore, v. 287, n. 5, p. E934-8. 2004.

BRASIL. Ministério do Planejamento, Orçamento e Gestão. Instituto Brasileiro de Geografia e Estatística - IBGE. Pesquisa de Orçamentos Familiares 2002 - 2003. Análise da disponibilidade domiciliar de alimentos e do estado nutricional no Brasil. Rio de Janeiro, 2004.

BRUCE, C.R.; HOY, A.J.; TURNER, N.; WATT, M.J.; ALLEN, T.L.; CARPENTER,K.; COONEY, G.J.; FEBBRAIO, M.A.; KRAEGEN, E.W. Overexpression of Carnitine Palmitoyltransferase-1 in Skeletal Muscle Is Sufficient to Enhance Fatty Acid Oxidation and Improve High-Fat Diet-Induced Insulin Resistance. Diabetes, New York, v. 58, p. 550-558, 2009.

BRYSON, J.M.; COONEY, G.J.; WENSLEY, v. R.; PHUYAL, J.L.; HEW, M.; DENYER, G.S.; CATERSON, I.D. High-fat feeding alters the response of rat PDH complex to acute changes in glucose and insulin. Am. J. Physiol., Baltimore, v. 268, n. 31, p. E752-757, 1995.

BUSE, M.G.; ROBINSON, K.A.; MARSHALL, B.A.; HRESKO, R.C.; MUECKLER, M.M. Enhanced $O$-GlcNAc protein modification is associated with insulin resistance in GLUT1-overexpressing muscles. Am. J. Physiol., Baltimore, v. 283, p. E241 - 250, 2002.

CHOMCZYNSKI, P.; SACCHI, N. Single-step method of RNA isolation by acid guanidinium thiocyanate-phenol-chloroform extraction. Anal. Biochem., Nova York, v. 162, p. 156-159, 1987.

COELHO, D.F.; GUALANO, B.; ARTIOLI, G.G.; ROSCHEL, H.; AMANO, M.; BENATTI, F.B.; FERNANDES, T.; BUENO Jr., C.R.; CÂMARA, N.O.; LANCHA JR., A.H. Exercise Training Attenuates Lipectomy-Induced Impaired Glucose Tolerance In Rats. Endocr. regul., Bratislava, v. 43, p. 107-116, 2009.

COMMERFORD, S.R.; FERNIZA, J.F.; BIZEAU, M.E.; THRESHER, J.S.; WILLIS, W.T.; MICHAEL J. PAGLIASSOTTI, M.J. Diets enriched in sucrose or fat increase 
gluconeogenesis and G-6-Pase but not basal glucose production in rats. Am. J. Physiol., Baltimore, v. 283, n.3, p. E545 - 555, 2002.

DEFRONZO, R. A.; FERRANNINI, E. Insulin resistance: a multifaceted syndrome responsible for NIDDM, obesity, hypertension, dyslipidemia, and atherosclerotic cardiovascular disease. Diabetes Care, New York, v. 14, p. 173-194, 1991.

DENGEL, D.R.; HAGBERG, J.M.; PRATLEY, R.E.; ROGUS, E.M.; GOLDBERG, A.P. Improvements in blood pressure, glucose metabolism, and lipoprotein lipids after aerobic exercise plus weight loss in obese, hypertensive middle-aged men. Metabolism, Philadelphia, v. 47, p. 1075-1082, 1998.

DESPRÉS, J.P.; LAMARCHE, B. Low intensity endurance exercise training, plasma lipoporotein and the risk of coronary heart disease. J. Intern. Med., Oxford, v. 236, p. 722, 1994.

DUPLUS, E.; GLORIAN, M.; FOREST, C. Fatty acid regulation of gene transcription. J. Biol. Chem., Baltimore, v. 275, p. 30749-30752, 2002.

ENGLISH, P.J.; GHATEI, M.A.; MALIK, I.A.; BLOOM, S.R.; WILDING, J.P. Food fails to suppress ghrelin levels in obese humans. J. Clin. Endocrinol. Metab., Philadelphia, v. 87, p. 2984, 2002.

FELBER, J.P.; GOLAY, A. Regulation of nutrient metabolism and energy expenditure. Metabolism, Philadelphia, v. 44, n. 2S, p. 4-9, 1995.

FESKENS, E.J.; LOEBER, J.G.; KROMHOUT, D. Diet and physical activity as determinants of hyperinsulinemia: the Zutphen Elderly Study. Am. J. Epidemiol., Baltimore, v. 140, p. 350 - 360, 1994.

FESTING, M.F.W. The inheritance of obesity in animal models of obesity. In: FESTING, M.F.W. Animal models of obesity. London: Oxford University Press, 1979. p. 15-37.

FLATT, J.P.; RAVUSSIN, E.; ACHESON, K.J.; JEQUIER, E. Effects of dietary fat on postprandial substrate oxidation and on carbohydrate and fat balances. J. Clin. Invest., New Haven, v. 76, p. 1019-24, 1985.

FLATT, J.P. Dietary fat, carbohydrate balance, and weight maintenance: effects of exercise. Am. J. Clin. Nutr., Bethesda, v. 45, p. 296-306, 1987. 
FLATT, J.P. Use and storage of carbohydrate and fat. Am. J. Clin. Nutr., Bethesda, v. 61S, p. 952-959, 1995.

FRANCISCHI, R.P.; OQUENDO, L.; CAMPOS, P.L.; FUTIGAMI, S.; NETO, S.R.C.;

LANCHA JR, A.H. Physical activity and nutritional control features a treatment of obesity in Brazilian women. In: INTERNATIONAL CONFERENCE OF BIOCHEMISTRY OF EXERCISE, 10., 1997, Sydney. Abstracts... Sydney: The University of Sydney, 1997. p. 40.

FRANCISCHI, R.P.; KLOPFER, M.; PEREIRA, L.O.; CAMPOS, P.L.; SAWADA, L. A.; SANTOS, R.; VIEIRA, P.; LANCHA JR, A. H. Efeito da intensidade da atividade física e da dieta hipocalórica sobre consumo alimentar, a composição corporal e a colesterolemia em mulheres obesas. Rev. Bras. Nutr. Clin., São Paulo, v. 14, p. 1-8, 1999a.

FRANCISCHI, R.P.; SANTOS, R.C.; VIEIRA, P.; FREITAS, C.S.; KLOPFER, M. PEREIRA, L.O; SAWADA, L.A.; CAMPOS, P.L.; LANCHA JR., A. H. Effects of exercise on dietary composition, metabolism and body composition of Brazilian obese women. Scand. J. Nutr., Lund, v. 43, n. 34S, p. 40S, 1999b.

FRANCISCHI, R.P.; PEREIRA, L.O.; FREITAS, C.S.; KLOPFER, M.; SANTOS, R.C.; VIERA, P.; LANCHA JR., A.H. Obesidade: atualização sobre sua etiologia, morbidade e tratamento. Rev. Nutr., Campinas, v. 13, p. 17-28, 2000.

FRANCISCHI, R.P.; PEREIRA, L.O.; LANCHA JR., A.H. Exercício, comportamento alimentar e obesidade: revisão dos efeitos sobre a composição corporal e parâmetros metabólicos. Rev. Paul. Educ. Fís., São Paulo, v. 15, p. 117-140, 2001.

FREDERICH, R.C.; HAMANN, A.; ANDERSON, S.; LÖLLMANN, B.; LOWELL, B.B.; FLIER, J.S. Leptin levels reflect body lipid content in mice: evidence for dietinduced resistance to leptin action. Nat. Med., New York, v. 1, n. 12, p. 13111314,1995 .

FREITAS, C.S.; KLOPFER, M.; VIEIRA, P.; FRANCISCHI, R.; SANTOS, R.; PEREIRA, L.; SAWADA,L.; CAMPOS, P.; LANCHA JR., A.H. Perfil das mulheres obesas que procuram o programa de atividade física da Escola de Educação Física e Esporte. In: CONGRESSO DE INICIAÇÃO CIENTÍFICA, 5., 1998, São Paulo. Anais... SIMPÓSIO DE PÓS GRADUAÇÃ̃O DA ESCOLA DE EDUCAÇÃO FÍSICA E ESPORTE DA UNIVESIDADE DE SÃO PAULO, 3., 1998, São Paulo. Anais... São Paulo: Universidade de São Paulo, 1998. p. 87-88. 
FRIEL, S.; CHOPRA, M.; SATCHER, D. Unequal weight: equity oriented policy responses to the global obesity epidemic BMJ, London, v. 335, p. 1241-1243, 2007.

FURLER, S.M.; OAKES, N.D.; WATKINSON, A.L.; KRAEGEN, E.W. A high-fat diet influences insulin-stimulated posttransport muscle glucose metabolism in rats. Metabolism, Philadelphia, v. 46, n. 9, p. 1101-1106, 1997.

GARCIA-ROVES, P.; HUSS, J.M.; HAN, D.H.; HANCOCK, C.R.; IGLESIASGUTIERREZ, E.; CHEN, M.; HOLLOSZY, J.O. Raising plasma fatty acid concentration induces increased biogenesis of mitochondria in skeletal muscle. PNAS, Washington, v. 104, p. 10709-10713, 2007.

GIANOTTI, M.; ROCA, P.; PALOU, A. Body weight and tissue composition in rats made obese by a cafeteria diet. Effect of 24 hour starvation. Horm. Metab. Res., Stuttgart, v. 20, p. 208-212, 1988.

GIMENO, S.G.; FERREIRA, S.R.; CARDOSO, M.A.; FRANCO, L.J.; IUNES, M. Weight gain in adulthood and risk of developing glucose tolerance disturbance: a study of a Japanese-Brazilian population. Japanese-Brazilian Diabetes Study Group. J. Epidemiol., Tokyo, v. 10, p. 103-110, 2000.

GOLAY, A.; FELBER, J.P.; MEYER, H.U.; CURCHOD, B.; MAEDER, E.; JÉQUIER, E. Study on lipid metabolism in obesity diabetes. Metabolism, Philadelphia, v. 33, p. 111-116, 1984.

GRUNDLEGER, M.L.; THENEN, S.W. Decreased insulin binding, glucose transport, and glucose metabolism in soleus muscle of rats fed a high fat diet. Diabetes, New York, v. 31, p. 232-237, 1982.

GRUNDY, S.M. Multifactorial causation of obesity: implications for prevention. Am. J. Clin. Nutr., Bethesda, v. 67S, p. 563- 572, 1998.

HAAPANEN, N.; MIILUNPALO, S.; OJA, P.; VUORI, I. Association between leisure time physical activity and 10-year body mass change among working-aged men and women. Int. J. Obes. Relat. Metab. Disord., London, v. 21; p. 288-296, 1997.

HAFFNER, S.M.; VALDEZ, R.A.; HAZUDA, H.P.; MITCHELL, B.D.; MORALES, P.A.; STERN, M.P. Prospective analysis of the insulin-resistance syndrome (syndrome X). Diabetes, New York, v. 41, p. 715 -722, 1992. 
HAN, D.; HANSEN, P.A.; HOST, H.H.; HOLLOSZY, J.O. Insulin resistance of muscle glucose transport in rats fed a high-fat diet: a reevaluation. Diabetes, New York, v. 46, p. 1761-1767, 1997.

HANSEN, P.A.; HAN, D.H.; MARSHALL, B.A.; NOLTE, L.A.; CHEN, M.M.; MUECKLER, M.; HOLLOSZY, J.O. A High Fat Diet Impairs Stimulation of Glucose Transport in Muscle. J. Biol. Chem., Baltimore, v. 273, p. 26157 - 26163, 1998.

HASSID, W.Z.; ABRAHAMS, S. Chemical procedures for analyses of polisaccharides. Methods Enzimol., New York, v. 3, p. 34-51, 1957.

HAUNER, H. Abdominal obesity and coronary heart disease: pathophisiology and clinical significance. Herz., Leipzig, v. 20, p. 47-55, 1995.

HAYAT, M. T. Fixation for Electron Microscopy. London: Academic Press, 1981.

HEDLEY, A.A.; OGDEN, C.L.; JOHNSON, C.L.; CARROLL, M.D.; CURTIN, L.R.; FLEGAL, K.M. Prevalence of Overweight and Obesity Among US Children, Adolescents, and Adults, 1999-2002. JAMA, Chicago, v. 291, p. 2847-2850, 2004.

HESPEL, P.; RITCHER, E.A. Glucose uptake and transport in contracting perfused rat muscle with different pre-contraction glycogen concentration. J. Physiol., London, v. 427, p. 347-359, 1990.

HILL, J.O.; PETERS, J.C. Environmental contributions to the obesity epidemic. Science, New York, v. 280, p. 1371-1374, 1998.

HILL, J.O.; MELANSON, E.L.; WYATT, H.T. Dietary fat intake and regulation of energy balance: implications for obesity. J. Nutr., Bethesda, v. 120, p. 284S-288S, 2000.

HOOD, D.A.; TERJUNG, R.L. Amino acid metabolism during exercise and following endurance training. Sports Med., Auckland, v. 9, n. 1, p. 23-35, 1990.

HUNNICUTT, J.W.; HARDY, R.W.; WILLIFORD, J.; MGCONALD, J.M. saturated fatty acid-induced insulin resistance in rat adipocytes. Diabetes, New York, v. 43, p. 540-545, 1994. 
ISHIDA, K.; MIZUNO, A.; MURAKAMI, T.; SHIMA, K. Obesity is necessary but not sufficient for the development of diabetes mellitus. Metabolism., Philadelphia, v. 45, n. 10, p. 1288-1295, 1996.

IVKOVIC-LAZAR, T.; LEPSANOVIC, L.; BABIC, L.; STOKIC, E.; TESIC, D.; MEDIC-STOJANOSKA, M. The metabolic X syndrome: 4 case reports. Med. Pregl., Serbo, v. 45, p. 210-214, 1992.

JAMES, W.P.T.; DAUNCEY, M.J.; JUNG, R.T.; SHETTY, P.S.; TRAYHURN, P. Comparisons of genetic models of obesity in animals with obesity in man. In: Festing, M.F.W. Animal models of obesity. London: Oxford University Press, 1979. p. 221-235.

JEBB, S.A. Obesity: from molecules to man. Proc. Nutr. Soc., Cambridge, v. 58, p. 1$14,1999$.

JOVE, M.; PLANAVILA, A.; SANCHEZ, R. M.; MERLOS, M.; LAGUNA, J. C.;VAZQUEZ-CARRERA, M. Palmitate induces tumor necrosis factor-alpha expression in $\mathrm{C} 2 \mathrm{C} 12$ skeletal muscle cells by a mechanism involving protein kinase $\mathrm{C}$ and nuclear factor-kappaB activation. Endocrinology, Baltimore, v. 147, n. 1, p. 552-61, 2006.

KAHN, B.B.; PEDERSEN, O. Suppression of GLUT4 expression in skeletal muscle of rats that are obese from high fat feeding but not from high carbohydrate feeding or genetic obesity. Endocrinology, Baltimore, v. 132, p. 13-22, 1993.

KATAN, M.B. Fatty acids and health: an update. Scand. J. Nutr., Lund, v. 43, n. 34S, p. 26S, 1999.

KAWANAKA, K.; NOLTE, L.A.; HAN, D.H.; HANSEN, P.A.; HOLLOSZY, J.O. Mechanisms underlying impaired GLUT-4 translocation in glycogen-supercompensated muscles of exercised rat. Am. J. Physiol., Baltimore, v. 279, p. E1311-1318, 2000.

KEYS, A.; ARAVANIS, C.; VAN BUCHEM, F.S.P.; BLACKBURN, H.W.; BUZINA, R. DJORDJEVIC, B.S. The diet and all-causes death rate in the seven country study. Lancet, Barcelona, v. 11, p. 58-61, 1981.

KIM, J.K.; WI, J.K.; YOUN, J.H. metabolic impairment precedes insulin resistance in skeletal muscle during high-fat feeding in rats. Diabetes, New York, v. 45, p. 651-658, 1996. 
KLOPFER, M.; FRANCISCHI, R.; CAMARGO, R.; VIEIRA, P.; OQUENDO, L.; FREITAS, C.S.; SAWADA, L.; CAMPOS, P.; LANCHA JR., A.H. Moderate energy restriction with or without aerobic exercise: a comparison of three methods. In: DIET AND THE METABOLIC SYNDROME - INTERNATIONAL SYMPOSIUM, 1999. Ystad Sweden. Abstracts... Sweden: Ystad, 1999. p. 65.

KOVES, T.R.; USSHER, J.R.; NOLAND, R.C.; SLENTZ, D.; MOSEDALE, M.; ILKAYEVA, O.; BAIN, J.; STEVENS, R.; DYCK, J.R.; NEWGARD, C.B.; LOPASCHUK, G.D.; MUOIO. D.M. Mitochondrial overload and incomplete fatty acid oxidation contribute to skeletal muscle insulin resistance. Cell Metab., Cambridge, v. 7,p. 45-56, 2008

KRAEGEN, E.W.; CLARK, P.W.; JENKINS, A.B.; DALEY, E.A.; CHISHOLM, D.J.; STORLIEN, L.H. Development of muscle insulin resistance after liver insulin resistance in high-fat-fed rats. Diabetes, New York, v. 40, p. 1397-1403, 1991.

KUCZMARSKI, R.J.; FLEGAL, K.M; CAMPBELL, S.M.; JOHNSON, C.L. Increasing prevalence of overweight among US adults: the National Health and Nutrition Examination Surveys, 1960 to 1991. JAMA, Chicago, v. 272, p. 205-211, 1994.

LANCHA JR., A.H. Papel da geração de oxaloacetato no exercício físico moderado em ratos: consequência da suplementação de aspartato e asparagina. 1993. Tese de Doutorado - Faculdade de Ciências Farmacêuticas da Universidade de São Paulo, São Paulo, 1993.

LANCHA JR., A.H.; RECCO, M.B.; CURI, R. Pyruvate carboxylase activity in the heart and skeletal muscles of the rat. Evidence for a stimulating effect of exercise. Biochem. Mol. Biol. Int., New York, v. 32, p. 483-489, 1994.

LANCHA JR., A.H.; RECCO, M.B.; ABDALLA, D.S.P.; CURI, R. Effect of of aspartate, asparagine and carnitina supplementation in the diet on metabolism of skeletal of skeletal muscle during a moderate exercise. Physiol. Behav., New York, v. 57, n. 2, p. 367-371, 1995a.

LANCHA JR., A.H.; HAN, D.H.; HANSEN, P.A.; HOLLOSZY, J.O. Effect of aspartate and asparagine supplementation in the glucose transport activity in epitrochlearis muscle. Med. Sci. Sports Exerc., Madison, v. 27S, p. 146, 1995 b.

LANCHA JR., A.H. Atividade física, suplementação nutricional de aminoácidos e resistência periférica à insulina. Rev. Paul. Educ. Fís., São Paulo, v. 10, p. 68-75, 1996. 
LANCHA JR., A.H. Efeito da suplementação de aminoácidos (aspartato e asparagina) sobre o transporte de glicose em músculo esquelético de ratos. Tese (Livre-Docência) Escola de Educação Física e Esporte da Universidade de São Paulo, São Paulo, 1997a.

LANCHA JR., A.H.; SANTOS, M.F.; PALANCH, A.C.; CURI, R. Supplementation of aspartate, asparagine and carnitine in the diet causes marked changes in the ultrastructure of soleus muscle. J. Submicrosc. Cytol. Pathol., Bologna, v. 29, n.3, p. 405-408, $1997 \mathrm{~b}$.

LANCHA JR., A.H. Proteína. In: Nutrição e metabolismo aplicado à atividade motora. São Paulo: Ed. Atheneu, 2002. p. 13-35.

LANCHA JR., A.H.; POORTMANS, J.R.; PEREIRA, L.O. The effect of five days of aspartate and asparagine supplementation on glucose transport activity in rat muscle. Cell Biochem. Funct., Chichster, 2009. In press.

LEBOVITZ, H.E. e BANERJI, M.A. Point: visceral adiposity is causally related to insulin resistance. Diabetes Care, Alexandria, v. 28, p. 2322-2325, 2005.

LEE, I.S.; SHIN, G., CHOUE, R. Shifts in Diet from High Fat to High Carbohydrate Improved Levels of Adipokines and Pro-inflammatory Cytokines in Mice Fed a Highfat Diet. Endocr. J., Tokyo, 2009. In press.

LICHTENSTEIN, A.H.; KENNEDY, E.; BARRIER, P.; DANFORD, D.; ERNST, N.D.; GRUNDY, S.M.; LEVEILLE, G.A.; HORN, L.V.; WILLIAMS, C.L.; BOOTH, S.L. Dietary fat consumption and health. Nutr. Rev., Mexico, v. 56, n. 5, p. S3-28, 1998. Part 2.

LITTLE, T.J.; HOROWITZ, M.; FEINLE-BISSET, C. Modulation by high-fat diets of gastrointestinal function and hormones associated with the regulation of energy intake: implications for the pathophysiology of obesity. Am. J. Clin. Nutr., Bethesda, v. 86, p. 531-41, 2007.

LLADÓ, I.; RODRÍGUEZ-CUENCA, S.; PUJOL, E.; MONJO, M.; ESTRANY, M.E.; ROCA, P.; PALOU, A. Gender effects on adrenergic receptor expression and lipolysis in white adipose tissue of rats. Obes. Res., Baton Rouge, v. 10, n. 4, p. 296-305, 2002.

LIU, H.Y.; ZHENG, G.; ZHU, H.; WOLDEGIORGIS G. Hormonal and nutritional regulation of muscle carnitine palmitoyltransferase I gene expression in vivo. Arch. Biochem. Biophys, New York, v. 465, p. 437-442, 2007 
MAHAN, L.K.; ESCOTT-STUMP, S. Krause: Alimentos, nutrição e dietoterapia. Trad. A. Favano. 9. ed. São Paulo: Roca, 1998.

MARON, D.J.; FAIR, J.M.; HASKELL, W.L. Saturated fat intake and insulin resistance in men with coronary artery disease. The Stanford Coronary Risk Intervention Project Investigators and Staff. Circulation, Dallas, v. 84, p. 2020 - 2027, 1991.

MARSHALL, S.; GARVEY, W.T.; TRAXINGER, R.R. New insights into the metabolic regulation of insulin action and insulin resistance: role of glucose and amino acids. FASEB J., Bethesda, v. 5, p. 3031-3036, 1991.

MARTINEZ, J.A. Body-weight regulation: causes of obesity. Proc. Nutr. Soc., Cambridge, v. 59, p. 337-345, 2000.

MATSUO, T.; SUZUKI, M. Beef tallow diet decreases lipoprotein lipase activities in brown adipose tissue, heart, and soleus muscle by reducing sympathetic activities in rats. J. Nutr. Sci. Vitaminol., Osaka, v. 40, n. 6, p. 569-581, 1994.

MATTHEWS, J.N.S.; ALTMAN, D.G.; CAMPBELL, M.J.; ROYSTON, P. Analysis of serial measurements in medical research. Br. Med. J., London, v. 300, p. 230-235, 1990.

MAYER, E.J.; NEWMAN, B.; QUESENBERRY, C.P.; SELBY, J.V. Usual dietary fat intake and insulin concentrations in healthy women twins. Diabetes Care, New York, v. 16, p. $1459-1469,1993$.

MCNAMARA, D.J.; HOWELL, W.H. Epidemiologic data linking diet to hyperlipidemia and arterioscleroses. Semin. Liver Dis., New York, v. 12, n. 4, p. 347$355,1992$.

MELBY, C.L.; COMMERFORD, S.R .; HILL, J.O. Exercise, macronutrient balance, and weight control. In: LAMB, D.R.; MURRAY, R. Perspectives in Exercise Science and Sports Medicine. Carmel: Cooper Publishing Group, 1998. p. 1-60. v. 11: Exercise, Nutrition, and Weight Control.

MILLER, G.D.; HRUPKA, B.J.; GIETZEN, D.W.; ROGERS, Q.R.; STERN, J.S. Rats on a macronutrient self-selection diet eat more meals from a single food cup. Appetite, London, v. 23, p. 67-78, 1994. 
MILLER, W.J.; SHERMAN, W.M.; DODD, H.; IVY, J.L. Influence of dietary carbohydrate on skeletal muscle glucose uptake. Am. J. Clin. Nutr., Bethesda, v. 41, p. 526-532, 1985.

MONTEIRO, C.A.; MONDINI, L.; SOUZA, A.L.M.; POPKIN, B.M. Da desnutrição para a obesidade: a transição nutricional no Brasil. In: MONTEIRO, C.A. Velhos e novos males da saúde no Brasil: a evolução do país e de suas doenças. São Paulo: Hcitec-NUPENS/USP, 1995a. p. 247-255.

MONTEIRO, C.A.; MONDINI, L.; SOUZA, A.L.M.; POPKIN, B.M. The nutrition transition in Brazil. Eur. J. Clin. Nutr., Basingstoke, v. 49, p. 105-113, 1995 b.

MONTEIRO, C.A.; CONDE, W.L. A tendência secular da obesidade segundo estratos sociais: nordeste e sudeste do Brasil, 1975-1989-1997. Arq. Bras. Endocrinol. Metab., São Paulo, v. 43, n. 3, p. 186-194, 1999.

MONTEIRO, C.A.; CONDE, W.L.; POPKIN, B.M. The Burden of Disease From Undernutrition and Overnutrition in Countries Undergoing Rapid Nutrition Transition: A View From Brazil. Am. J. Public Health, Washington, v. 94, p. 433-434, 2004.

MONTEIRO,C.A.; CONDE, W.L.; POPKIN, B.M. Income-Specific Trends in Obesity in Brazil: 1975-2003. Am. J. Public Health, Washington, v. 97, p. 1808-1812, 2007.

MOORE, B.J. The cafeteria diet-an inappropriate tool for studies of thermogenesis. J. Nutr., Bethesda, v. 117, n. 2, p. 227-231, 1987.

NASCIMENTO, E.B.; FODOR, M.; VAN DER ZON, G.C.; JAZET, I.M.; MEINDERS, A.E.; VOSHOL, P.J.; VLASBLOM, R.; BAAN, B.; ECKEL, J.; MAASSEN, J.A.; DIAMANT, M.; OUWENS, D.M. Insulin-mediated phosphorylation of the proline-rich Akt substrate PRAS40 is impaired in insulin target tissues of high-fat diet-fed rats. Diabetes, New York, v. 55, p. 3221-3228, 2006.

NATIONAL CENTER FOR HEALTH STATISTICS. Chartbook on Trends in the Health of Americans. Health, United States, Hyattsville, MD: Public Health Service, 2006.

NEWSHOLME, E.A.; LEECH, A.R. Biochemistry for the medical sciences. New York: John Willey, 1988. 
NIELSEN, S.; GUO, Z.; JOHNSON, C.M.; HENSRUD, D.D.; JENSEN, M.D. Splanchnic lipolysis in human obesity. J. Clin. Invest., New Hansen, v. 113, p. 1582-8, 2004.

OAKES, N.D; COONEY, G.J.; CAMILLERI, S.; CHISHOLM, D.J.; KRAEGEN, E.W. Mechanisms of liver and muscle insulin resistance induced by chronic high-fat feeding. Diabetes, New York, v. 46, p. 1768-1774, 1997.

O'DEA, K. Westernization and non-insulin-dependent diabetes in Australian Aborigines. Ethn. Dis., Atlanta , v. 1, p. 171-187, 1991.

PAGLIASSOTTI, M.J.; HORTON, T.J.; GAYLES, E.C.; KOPPENHAFER, T.A.; ROSENZWEIG, T.D.; HILL, J.O. Reduced insulin suppression of glucose appearence is related to susceptibility to dietary obesity in rats. Am. J. Physiol., Baltimore, v. 272, n. 41, p. R1264-1270, 1997.

PAGLIASSOTTI, M.J.; GAYLES, E.C.; PODOLIN, D.A.; WEI, Y.; MORIN, C.L. Developmental stage modifies diet-induced peripheral insulin resistance in rats. Am. J. Physiol., Baltimore, v. 278, p. R66-73, 2000.

PAN, D.D.; LILLIOJA, S.; KRIKETOS, A.D; MILNER, M.R.; BAUR, L.A.; BOGARDUS, C.; JENKINS, A.B.; STORLIEN, L.H. Skeletal muscle triglyceride levels are inversely related to insulin action. Diabetes, New York, v. 46, p. 983-988, 1997.

PARKER, D.R.; WEISS, S.T.; TROISI, R.; CASSANO, P.A.; VOKONAS, P.S.; LANDSBERG, L. Relationship of dietary saturated fatty acids and body habitus to serum insulin concentrations: the Normative Aging Study. Am. J. Clin. Nutr., Bethesda, v. 58, p. 129-136, 1993.

PARRY-BILLINGS, M.; NEWSHOLME, E.A. The possible role of glutamine substrate cycles in skeletal muscle. Biochem. J., London, v. 279, p. 327-328, 1991. Part 1.

PASSONNEAU, J.V.; LOWRY, O.H. Enzymatic analysis-a practical guide. New Jersey: Humana Press, 1993.

PEREIRA, L.O.; FRANCISCHI, R.P.; KLOPFER, M.; PERROTI, A.C.; CAMPOS, P.L.; SAWADA, L.A.; COSTA, S.R.; LANCHA JR., A.H. Different intensities of physical activities with or without hypocaloric diet: effects on body composition, food consumption and plasmatic profile in obese women. Med. Sci. Sports Exerc., Madison, v. 30, p. S238, 1998. 
PEREIRA, L.O.; FRANCISCHI, R.P.; KLOPFER, M.; SAWADA, L.A.; SANTOS, R.; VIEIRA, P.; CAMPOS, P.L.; LANCHA JR., A.H. Obesidade e sua Implicações - Ação da Atividade Física e Controle Nutricional. Rev. Bras. Nutr. Clin., São Paulo, v. 14, p. 9-17, 1999a.

PEREIRA, L.O.; KLOPFER, M.; VIEIRA, P.; FRANCISCHI, R.P.; CAMARGO, R.S.; FREITAS, C.; SAWADA, L.; CAMPOS, P.; LANCHA JR., A.H. The evaluation of the best strategy to increase muscle mass and improve health in obese women. Proc. Nutr. Soc., Cambridge, v. 59, p. 99A, 1999 b.

PEREIRA, L.O. Protocolo de indução de obesidade em ratas a partir do perfil de ingestão alimentar de mulheres obesas brasileiras. Campinas. Tese (Mestrado) Instituto de Biologia da Universidade Estadual de Campinas, São Paulo, 2003a.

PEREIRA, L.O.; FRANCISCHI, R.P.; LANCHA JR., A.H. Obesidade: hábitos nutricionais, sedentarismo e resistência à insulina. Arq. Bras. Endocrinol. Metabol., São Paulo, v. 47, p. 117-127, 2003 b.

PEREIRA, L.O.; LANCHA JR., A.H. Effect of Insulin and Contraction Up on Glucose Transport in Skeletal Muscle. Prog. Biophys. Mol. Biol., Oxford, v. 84, p. 1-27, 2004.

PICARD, F.; BOIVIN, A.; LALONDE, J.; DESHAIES, Y. Resistance of adipose tissue lipoprotein lipase to insulin action in rats fed an obesity-promoting diet. Am. J. Physiol., Baltimore, v. 282, p. E412-418, 2002.

PIKE, M. Industrial nutrition. London: MaGConald, 1950.

POPKIN, B.M.; DOAK, C.M. The obesity epidemic is a worldwide phenomenon. Nutr. Rev., México, v. 56, p. 106-114, 1998.

POWER, G.W.; NEWSHOLME, E.A. Dietary Fatty Acids Influence the Activity and Metabolic Control of Mitochondrial Carnitine Palmitoyltransferase I in Rat Heart and Skeletal Muscle. J. Nutr., Bethesda, v. 127, p. 2142-2150, 1997

PRENTICE, A.M. Manipulation of dietary fat and energy density and subsequent effects on substrate flux and food intake. Am. J. Clin. Nutr., Bethesda, v. 67S, p. 535S541, 1998. 
POMPLUN, D.; VOIGT, A.; SCHULZ, T.J.; THIERBACH, R.; PFEIFFER, A.F.; RISTOW, M. Reduced expression of mitochondrial frataxin in mice exacerbates dietinduced obesity. PNAS, Washington, v. 104, p. 6377-6381, 2007.

RANDLE, P.J.; HALES, C.N.; GARLAND, P.B.; NEWSHOLME, E.A. The glucose fatty-acid cycle: its role in insulin sensitivity and the metabolic disturbances of diabetes mellitus. Lancet, Barcelona, v. 6, p. 785-789, 1963.

RAUBENHEIMER, P.J.; NYIRENDA, M.J.; WALKER, B.R. A choline-deficient diet exacerbates fatty liver but attenuates insulin resistance and glucose intolerance in mice fed a high-fat diet. Diabetes, New York, v. 55, p. 2015-20, 2006.

REN, J.M.; MARSHALL, B.A.; GULVE, E.A., GAO, J.; JOHNSON, D.W.; HOLLOSZY, J.O.; MUECKLER, M. Evidence from transgenic mice that glucose transport is rate-limiting for glycogen deposition and glycolysis in skeletal muscle. $\underline{\mathbf{J}}$. Biol. Chem., Baltimore, v. 268, p. 16113-16115, 1993.

RENNIE, M.J.; EDWARDS, R.H.; KRYWAWYCH, S.; DAVIES, C.T.; HALLIDAY, D.; WATERLOW, J.C.; MILLWARD, D.J. Effect of exercise on protein turnover in

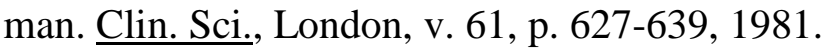

REYNOLDS, T.H.; CINQUINO, N.; ANTHONY, M.; PHELPS, C.B.; BERK, E.Z. Insulin Resistance without Elevated Mammalian Target of Rapamycin Complex 1 Activity in Muscles of Mice Fed a High Fat Diet. J. Appl. Physiol., Washington, 2009. In press.

ROBINSON, K.A.; SENS, D.A.; BUSE, M.G. Pre-exposure to glucosamine induces insulin resistance of glucose transport and glycogen synthesis in isolated rat skeletal muscles. Diabetes, New York, v. 42, p. 1333-1346, 1993.

ROCCHINI, A.P.; MARKER, P.; CERVENKA, T. Time course of insulin resistance associated with feeding dogs a high-fat diet. Am. J. Physiol., Baltimore, v. 272, n. 35, p. E147-154, 1997.

ROLLS, B.J.; SHIDE, D.J. The influence of dietary fat on food intake and body weight. Nutr. Rev., México, v. 50, p. 283-290, 1992.

ROMIEU, I.; WILLETT, W.C.; STAMPFER, M.J.; COLDITZ, G.A.; SAMPSON, L.; ROSNER, B.; HENNEKENS, C.H.; SPEIZER, F.E. Energy intake and other determinants of relative weight. Am. J. Clin. Nutr., Bethesda, v. 47, p. 406 - 412, 1988. 
ROTHWELL, N.J.; STOCK, M.J. The cafeteria diet as a tool for studies of thermogenesis. J. Nutr., Bethesda, v. 118, n.8, p. 925-928, 1988.

ROY,C.; PAGLIALUNGA, S.; FISETTE,A.; SCHRAUWEN, P.; MOONENKORNIPS, E.; ST-ONGE, J.; HESSELINK,M.K.; RICHARD, D.; JOANISSE, D.R.; CIANFLONE, K. Shift in metabolic fuel in acylation-stimulating protein-deficient mice following a high-fat diet. Am. J. Physiol., Baltimore, v. 294, p. E1051-1059, 2008.

RYU, M.H.; SOHN, H,S,; HEO, Y.R.; MOUSTAID-MOUSSA, N.; CHA, Y.S. Differential regulation of hepatic gene expression by starvation versus refeeding following a high-sucrose or high-fat diet. Nutrition, Burbank, v. 21, p. 543-552, 2005

SALTIEL, A.R. You are what you secrete. Nat. Med., New York, v. 7, p. 887-888, 2001.

SAWADA, L.A.; COSTA, A.S.; MARQUEZI, M.L.; PEREIRA, L.O.; COSTA ROSA, L.F.B.P.; LANCHA JR., A.H. The effect of the oral glutamine supplementation in the development of insulin resistance on rats muscles. Med. Sci. Sports Exerc., Madison, v. 30, p. S17, 1998.

SCHULZ, L.O.; SCHOELLER, D.A. A compilation of total daily energy expenditures and body weights in healthy adults. Am. J. Clin. Nutr., Bethesda, v. 60, p. 676-681, 1994.

SCLAFANI, A.; SPRINGER, D. Dietary obesity in adult rats: similarities to hypothalamic and human obesity syndromes. Physiol. Behav., New York, v. 17, p. 461471, 1976a.

SCLAFANI, A.; SPRINGER, D.; KLUGE, L. Effect of quinine adulteration on the food intake and body weight of obese and non-obese hypothalamic hyperphagic rats. Physiol. Behav., New York, v. 16, p. 631-640, 1976 b.

SCLAFANI, A. Dietary obesity models. In: BJÖRNTORP, P.; BRODOFF, B. N. Obesity. Philadelphia: J. B. Lippincott Company, 1992. p. 241-248.

SEGUÉS, T.; SALVADÓ, J.; AROLA, L.; ALEMANY, M. Long-term effects of cafeteria diet feeding on young wistar rats. Biochem. Mol. Biol. Int., New York, v. 22, p. 321-328, 1994. 
SEIDELL, J.C. Obesity insulin resistance and diabetes - a worldwide epidemic? In: DIET AND THE METABOLIC SYNDROME - INTERNATIONAL SYMPOSIUM, 1999. Sweden. Abstracts... Sweden: Ystad, 1999. p. 20.

SHARMA, B.; SALUNKE, R.; SRIVASTAVA, S.; MAJUMDER, C.; ROY, P. Effects of guggulsterone isolated from Commiphora mukul in high fat diet induced diabetic rats. Food. Chem. Toxicol., Oxford, v. 47, p. 2631-2639, 2009.

SHINNICK, F.L.; HARPER, A.E. Biochim Biophys Acta, Amsterdam, v. 437, p. 477486, 1976.

SICHIERI, R. Dietary patterns and their association with obesity in Brazilian city of Rio de Janeiro. Obes. Res., Baton Rouge, v. 10, p. 42-49, 2002.

SMITH, S.R.; DE JONGE, L.; ZACHWIEJA, J.J.; ROY, H.; NGUYEN, T.; ROOD, J.C. WINDHAUSER, M.M.; BRAY, G.A. Fat and carbohydrate balances during adaptation to a high-fat. Am. J. Clin. Nutr., Bethesda, v. 71, p. 450-457, 2000.

SOLINI, A.; BONORA, E.; BONADONNA, R.; CASTELLINO, P.; DEFRONZO, R.A. Protein Metabolism in Human Obesity: Relationship with Glucose and Lipid Metabolism and with Visceral Adipose Tissue. J. Clin. Endocrinol. Metab., Springfield, v. 82, p. $2552-2558,1997$.

SPARKS, L. M.; XIE, H.; KOZA, R. A.; MYNATT, R.; HULVER, M. W.; BRAY, G. A.;SMITH, S. R. A high-fat diet coordinately downregulates genes required for mitochondrial oxidative phosphorylation in skeletal muscle. Diabetes, New York, v. 54, p. 1926-33. 2005.

STEIN, D.T.; STEVENSON, B.E.; CHESTER, M.W.; BASIT, M.; DANIELS, M.B.; TURLEY, S.D. The insulinotropic potency of fatty acids is influenced profoundly by their chain length and degree of saturation. J. Clin. Invest., New Haven, v. 100, p. 398403, 1997.

STORLIEN, L.H.; JAMES, D.E.; BURLEIGH, K.M.; CHISHOLM, D.J.; KRAEGEN, E.W. Fat feeding causes widespread in vivo insulin resistance, decreased energy expenditure, and obesity in rats. Am. J. Physiol., Baltimore, v. 251, n. 14, p. E576-583, 1986.

STORLIEN, L.H.; JENKINS, A.B.; CHISHOLM, D.J; PASCOE, W.S.; KHOURI, S.; KRAEGEN, E.W. Influence of dietary fat composition on development of insulin 
resistance in rats - relationship to muscle triglyceride and $\omega$-3 fatty acids in muscle phospholipid. Diabetes, New York, v. 40, p. 280-289, 1991.

STORLIEN, L.H.; OAKES, N.D.; PAN, D.A.; KUSUNOKI, M.; JENKINS, A.B. Syndrome of insulin resistance in the rat-inducement by diet and amelioration with benfluorex. Diabetes, New York, v. 42, p. 457-462, 1993.

STORLIEN, L.H.; BAUR, L.A.; KRIKETUS, A.D.; PAN, D.A.; COONEY, G.J.; JENKINS, A.B.; CALVERT, G.D.; CAMPBELL, L.V. Dietary fats and insulin action. Diabetologia, Heidelberg, v. 39, p. 621-631, 1996a.

STORLIEN, L.H.; PAN, D.A.; KRIKETOS, A.D.; O'CONNOR, J.; CATERSON, I.D.; COONEY, G.J.; JENKINS, A.B.; BAUR, L.A. Skeletal muscle membrane lipids and insulin resistance. Lipids; Chicago, v. 31S, p. S261-265, 1996 b.

STUBBS, R.J.; HARBRON, C.G.; MURGATROYD, P.R.; PRENTICE, A.M. Covert manipulation of dietary fat and energy density: effect on substrate flux and food intake in men eating ad libitum. Am. J. Clin. Nutr., Bethesda, v. 62, p. 316-29, 1995.

STUNKARD, A.J.; WADDEN, T.A. Psychological aspects of human obesity. In: Björntorp, P.; Brodoff, B. N. Obesity. Philadelphia: J. B. Lippincott Company, 1992. p. 352-360.

SUZUKI, K.; OHNO, S. Calcium activated neutral protease--structure-function relationship and functional implications. Cell Struct. Funct., Tokyo, v. 15, p. 1-6, 1990.

SWINBURN, B.; RAVUSSIN, E. Energy balance or fat balance? Am. J. Clin. Nutr., Bethesda, v. 57S, p. 766S-771, 1993.

TAGLE, M. A. Nutrição. Trad. I. S. Martins. São Paulo: Artes Médicas, 1981.

TAKEUCHI, H.; MATSUO, T.; TOKUYAMA, K.; SHIMOMURA, Y.; SUZUKI, M. Diet-induced thermogenesis is lower in rats fed a lard diet than in those fed a high oleic safflower oil diet, a safflower oil diet or a linseed oil diet. J. Nutr., Bethesda, v. 125, n.4, p. 920-925, 1995.

TAKEUCHI, H.; MATSUO, T.; TOKUYAMA, K.; SUZUKI, M. Effect of dietary fat type on beta-oxidation of brown adipose tissue and $\mathrm{Na}+$ channel density of brain nerve membrane in rats. J. Nutr. Sci. Vitaminol., Osaka, v. 42, n.2, p. 161-166, 1996. 
TAOUIS, M.; DAGOU, C.; STER, C.; DURAND, G.; LE PINAULT, M.; DELARUE, J. N-3 Polyunsaturated fatty acids prevent the defect of insulin receptor signaling in muscle. Am. J. Physiol., Baltimore, v. 282, p. E664-671, 2002.

TEBBEY, P.W.; MCGOWAN, K.M.; STEPHENS, J.M.; BUTTKE, T.M.; PEKALA, P.H. Arachidonic acid down-regulates the insulin-dependent glucose transporter gene (GLUT4) in 3T3-L1 adipocytes by inhibiting transcription and enhancing mRNA turnover. J. Biol. Chem., Baltimore, v. 269, p. 639-644, 1994.

TOWNSEND, K.L.; LORENZI, M.M.; WIDMAIER, E.P. High-fat diet-induced changes in body mass and hypothalamic gene expression in wild-type and leptindeficient mice. Endocrine., Totowa, v. 33, p. 176-188, 2008.

TRAXINGER, R.R; MARSHALL, S.L. Coordinated regulatin of Glutamine: Fructose6-phosphate amidotransferase activity by insulin, glucose, and glutamine. J. Biol. Chem., Baltimore, v. 266, n. 16, p. 10148-10154, 1991.

TREMBLAY, A.; ALMÉRAS, N.; BOER, J.; KRANENBARG, E. K.; DESPRÉS, J.P. Diet composition and postexercise energy balance. Am. J. Clin. Nutr., Bethesda, v. 59, p. 975-979, 1994.

TZATSOS, A.; KONSTANTIN, V. Kandror Nutrients Suppress Phosphatidylinositol 3Kinase/Akt Signaling via Raptor-Dependent mTOR-Mediated Insulin Receptor Substrate 1 Phosphorylation. Mol. Cell. Biol., Washington, v. 26, p. 63-76, 2006.

VAN AMELSVOORT, J.M.M.; VAN DER BECK, A.; STAM, J.J.; HOUTSMULLER, U.M.T. Dietary influence on the insulin function in the Epididymal fat cell of the wistar rat. I-Effect of type of fat. Ann. Nutr. Metab., Basel, v. 32, p. 138-148, 1988.

WANG, H.; STORLIEN, L.H.; HUANG, X.F. Effects of dietary fat types on body fatness, leptin, and ARC leptin receptor, NPY, and AgRP mRNA expression. Am. J. Physiol., Baltimore, v. 282, p. E1352-9, 2002.

WATARAI, T.; KOBAYASHI, M.; YAKAT, Y.; SASAOKA, T.; IWASAKI, M.; SHIGETA, Y. Alteration of insulin-receptor kinase activity by high fat feeding. Diabetes, New York, v. 37, p. 1397-1404, 1988.

WELLE, S.; BARNARD, R.R.; STATT, M.; AMATRUDA, J.M. Increased protein turnover in obese women. Metabolism, Philadelphia, v. 41, n. 9, p. 1028-1034, 1992. 
WELLE, S.; STATT, M.; BARNARD, R.; AMATRUDA, J.M. Differential effect of insulin on whole-body proteolysis and glucose metabolism in normal-weight, obese, and reduced-obese women. Metabolism, Philadelphia, v. 43, n. 4, p. 441-445, 1994.

WEISS, E.P.; BRANDAUER, J.; KULAPUTANA, O.; GHIU, I.A.; WOHN, C.R.; PHARES, D.A.; SHULDINER, A.R.; HAGBERG, J.M. FABP2 Ala54Thr genotype is associated with glucoregulatory function and lipid oxidation after a high-fat meal in sedentary nondiabetic men and women. Am. J. Clin. Nutr., Bethesda, v. 85, p. 102-108, 2007.

WEST, D.B.; YORK, B. Dietary fat, genetic predisposition, and obesity: lessons from animal models. Am. J. Clin. Nutr., Bethesda, v. 67, p. 505S-512, 1998.

WORLD HEALTH ORGANIZATION. Diet, nutrition and the prevention of chronic diseases. Geneva: WHO, 1990. (Technical Report Series, v. 797).

WORLD HEALTH ORGANIZATION. Physical Status: the use and interpretation of anthropometry. Geneva: WHO, 1995. (Technical Report Series, v. 854).

WORLD HEALTH ORGANIZATION. Obesity - preventing and managing the global epidemic. Geneva: WHO, 1998. (Report of a WHO Consultation on Obesity).

WILKES, J.J.; BONEN, A.; BELL, R.C. A modified high-fat diet induces insulin resistance in rat skeletal muscle but not adipocytes. Am. J. Physiol., Baltimore, v. 275, n. 38, p. E679-686, 1998.

WILLET, W. Is dietary fat a major determinant of body fat? Am. J. Clin. Nutr., Bethesda, v. 67, p. 556S-562, 1998.

YORK, D.A. Genetic models of animal obesity. In: BJÖRNTORP, P.; BRODOFF, B. N. Obesity. J. B. Philadelphia: Lippincott Company, 1992. p. 233-240.

YKI-JÄRVINEN, H.; VIRKAMÄKI, A.; DANIELS, M.C.; MCCLAIN, D.; GOTTSCHALK, W.K. Insulin and glucosamine infusions increase O-linked N-acetylglucosamine in skeletal muscle proteins in vivo. Metabolism., Philadelphia, v. 47, n. 4, p. 449-455, 1998.

YU, R.; KIM, C. S.; KWON, B. S.;KAWADA, T. Mesenteric adipose tissue-derived monocyte chemoattractant protein-1 plays a crucial role in adipose tissue macrophage 
migration and activation in obese mice. Obesity, Silver Spring, v. 14, n. 8, p. 13531362, 2006.

ZHANG, W.M.; KUCHÁR, S.; MOZES, S. Body fat and RNA content of tha VMH cells in rats neonatally treated with monosodium glutamate. Brain Res. Bull., Elmsford, v. 35, n. 4, p. 383-385, 1994.

ZIERATH, J.R. In vitro studies of human skeletal muscle: Hormonal and metabolic regulation of glucose transport. Acta Physiol. Scand., Stockholm, v. 155, p. S626, 1995.

ZIERATH, J.R.; HOUSEKNECHT, K.L.; GNUDI, L.; KAHN, B.B. High-fat feeding impairs insulin-stimulated GLUT-4 recruitment via an early insulin-signaling defect. Diabetes, New York, v. 46, p. 215-223, 1997. 